\title{
Multiband Split-Ring Resonator Based Planar Inverted-F Antenna for 5G Applications
}

\author{
Muhammad Kamran Ishfaq, ${ }^{1,2}$ Tharek Abd Rahman, \\ Hassan Tariq Chattha, ${ }^{3}$ and Masood Ur Rehman ${ }^{4}$ \\ ${ }^{1}$ Wireless Communication Centre, Universiti Teknologi Malaysia, Johor, Malaysia \\ ${ }^{2}$ Department of Electrical Engineering, Government College University, Faisalabad, Pakistan \\ ${ }^{3}$ Department of Electrical Engineering, Faculty of Engineering, Islamic University in Madinah, Al-Madinah, Saudi Arabia \\ ${ }^{4}$ Department of Computer Science and Technology, University of Bedfordshire, Luton, UK
}

Correspondence should be addressed to Muhammad Kamran Ishfaq; kamranzarrar@gmail.com

Received 9 September 2016; Revised 1 January 2017; Accepted 2 March 2017; Published 21 March 2017

Academic Editor: Renato Cicchetti

Copyright (C) 2017 Muhammad Kamran Ishfaq et al. This is an open access article distributed under the Creative Commons Attribution License, which permits unrestricted use, distribution, and reproduction in any medium, provided the original work is properly cited.

$5 \mathrm{G}$, the fifth generation of wireless communications, is focusing on multiple frequency bands, such as $6 \mathrm{GHz}, 10 \mathrm{GHz}, 15 \mathrm{GHz}$, $28 \mathrm{GHz}$, and $38 \mathrm{GHz}$, to achieve high data rates up to $10 \mathrm{Gbps}$ or more. The industry demands multiband antennas to cover these distant frequency bands, which is a task much more challenging. In this paper, we have designed a novel multiband split-ring resonator (SRR) based planar inverted-F antenna (PIFA) for $5 \mathrm{G}$ applications. It is composed of a PIFA, an inverted-L parasitic element, a rectangular shaped parasitic element, and a split-ring resonator (SRR) etched on the top plate of the PIFA. The basic PIFA structure resonates at $6 \mathrm{GHz}$. An addition of a rectangular shaped parasitic element produces a resonance at $15 \mathrm{GHz}$. The introduction of a split-ring resonator produces a band notch at $8 \mathrm{GHz}$, and a resonance at $10 \mathrm{GHz}$, while the insertion of an inverted-L shaped parasitic element further enhances the impedance bandwidth in the $10 \mathrm{GHz}$ band. The frequency bands covered, each with more than $1 \mathrm{GHz}$ impedance bandwidth, are $6 \mathrm{GHz}(5-7 \mathrm{GHz}), 10 \mathrm{GHz}(9-10.8 \mathrm{GHz})$, and $15 \mathrm{GHz}(14-15 \mathrm{GHz})$, expected for inclusion in next-generation wireless communications, that is, 5G. The design is simulated using Ansys Electromagnetic Suite 17 simulation software package. The simulated and the measured results are compared and analyzed which are generally in good agreement.

\section{Introduction}

5th-generation wireless systems, abbreviated as $5 \mathrm{G}$, are the proposed next wireless communication standards beyond the current 4G/IMT-advanced standards. 5G will increase the user capacity up to many billion and the data rate up to $10 \mathrm{Gbps}$. It will support a real-time wireless control, the device-to-device communication, allowing a reduction of power consumption by a factor of 1000 [1-4]. This next generation of wireless communications is focusing on multiple bands in the frequency range from $6 \mathrm{GHz}$ to $100 \mathrm{GHz}[2,5]$. For 5G, the antennas for handheld devices will need to operate within multiple frequency bands, while being low-profile and compact. Hence, there is a need for compact multiband antenna design approach to cover these several frequency bands. Planar inverted-F antenna (PIFA) has been a popular candidate in portable wireless systems due to its appealing features, such as low-profile, ease of fabrication, and robustness $[6,7]$, and it does not require any matching network when connected with the $50 \Omega$ coaxial input [8]. A wide range of multiband PIFA designs for wireless applications is found in the literature [9-14]. Over the last decade, the multiband antennas used in cellular devices cover frequency bands which are comparatively closer to each other, that is, $900 \mathrm{MHz}, 1.8 \mathrm{GHz}, 2.45 \mathrm{GHz}$, and so forth. The design of a multiband antenna for covering the far away frequency bands such as $6 \mathrm{GHz}, 10 \mathrm{GHz}, 15 \mathrm{GHz}, 28 \mathrm{GHz}$, and $38 \mathrm{GHz}$ expected for $5 \mathrm{G}$ [5] is a task much more challenging. Therefore, in this paper, we have designed a multiband split-ring resonator (SRR) based modified PIFA with the additions of a rectangular shaped and an inverted-L shaped 


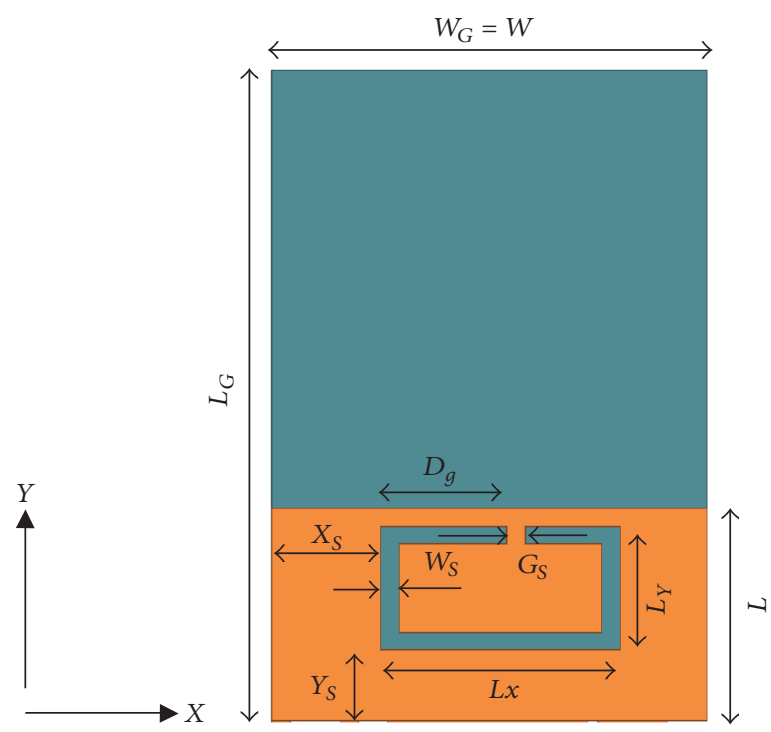

(a)

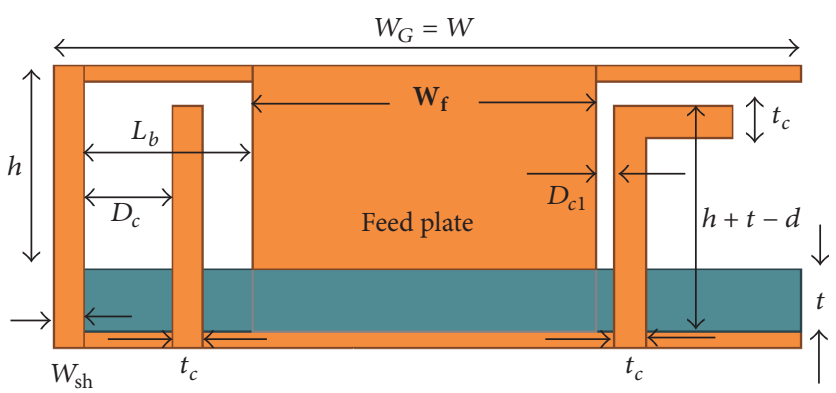

(b)

Figure 1: Geometry of an SRR based PIFA. (a) Top view; (b) side view.

parasitic element. It covers $6 \mathrm{GHz}, 10 \mathrm{GHz}$, and $15 \mathrm{GHz}$, distant frequency bands, simultaneously, expected for $5 \mathrm{G}$.

\section{Antenna Configuration}

The assembly of the designed PIFA is shown in Figure 1. It is composed of a radiating top plate of width $W$ and length $L$ and the ground plane of width $W_{G}$ and length $L_{G}$. The height of the top plate above the substrate is $h$, filled with air. The sizes of the feeding and the shorting plates are $W_{f} \times h$ and $W_{\text {sh }} \times(h+t)$, respectively, where $W_{f}$ is the width of the feeding plate, $W_{\text {sh }}$ is the width of the shorting plate, and $t$ is the thickness of the substrate. The separation between the feeding plate and the shorting plate is $L_{b}$. The substrate used is FR4, with a relative permittivity of 4.4 and a thickness $t=1 \mathrm{~mm}$. An inverted-L shaped parasitic element is introduced at a separation of $D_{c 1}$ from the feeding plate, whereas a rectangular shaped parasitic element is inserted at a distance, $D_{c}$, from the shorting plate. The heights and the widths of both the inverted-L and rectangular shaped parasitic elements are identical and equal to $(h-d)+t$ and $t_{c}$, respectively, where $d$ is the vertical gap between the top plate and the parasitic elements.

The top plate incorporates a split-ring resonator (SRR) introduced at a distance, $X_{S}$, from the horizontal edge and at a distance, $Y_{S}$, from the vertical edge of the radiating top plate. $W_{S}$ is the width of the SRR and $L_{X}$ and $L_{Y}$ are the lengths of the SRR along the horizontal and vertical sides of the top plate, respectively. The gap slot of the SRR is present at a distance, $D_{g}$, from the vertical side of the SRR. The fabricated prototype of the SRR based PIFA, for the measurement purpose, is shown in Figure 2. The antenna is excited by a semirigid cable in such a way that the braided outer conductor is shorted to the ground and the inner conductor is soldered to the feeding plate of the SRR based PIFA, as shown in Figure 2 [15]. An SMA connector is connected to the other end of the semirigid cable. This feeding mechanism reduces the coupling between the antenna and the SMA connector.

\section{Design Approach and Parametric Study}

For this multiband split-ring resonator based PIFA, a step by step design approach is adopted to attain the desired goals. Initially, a simple wideband PIFA is designed for $6 \mathrm{GHz}$ frequency band. The wide bandwidth is achieved by adjusting the widths of the feeding and the shorting plates [16]. Further, an inverted-L shaped parasitic element is introduced towards the right side of the feeding plate so to shift the resonance at about $8 \mathrm{GHz}$. Next, a rectangular shaped parasitic element is inserted towards the right side of the shorting plate. The 


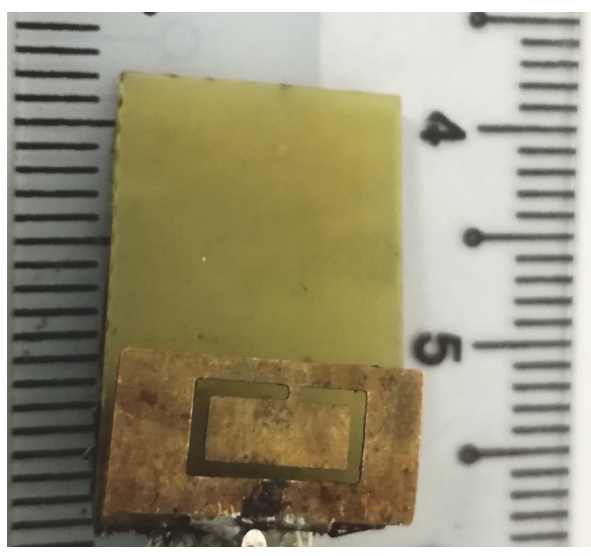

(a)

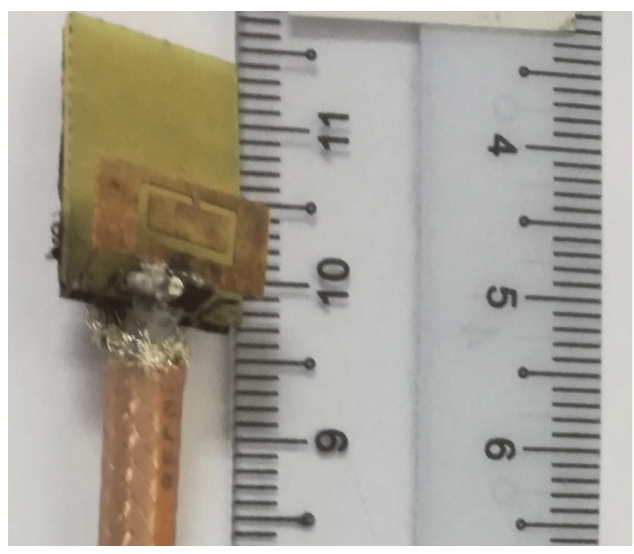

(b)

FIGURE 2: Fabricated SRR based PIFA for measurements. (a) Top view; (b) 3D view.

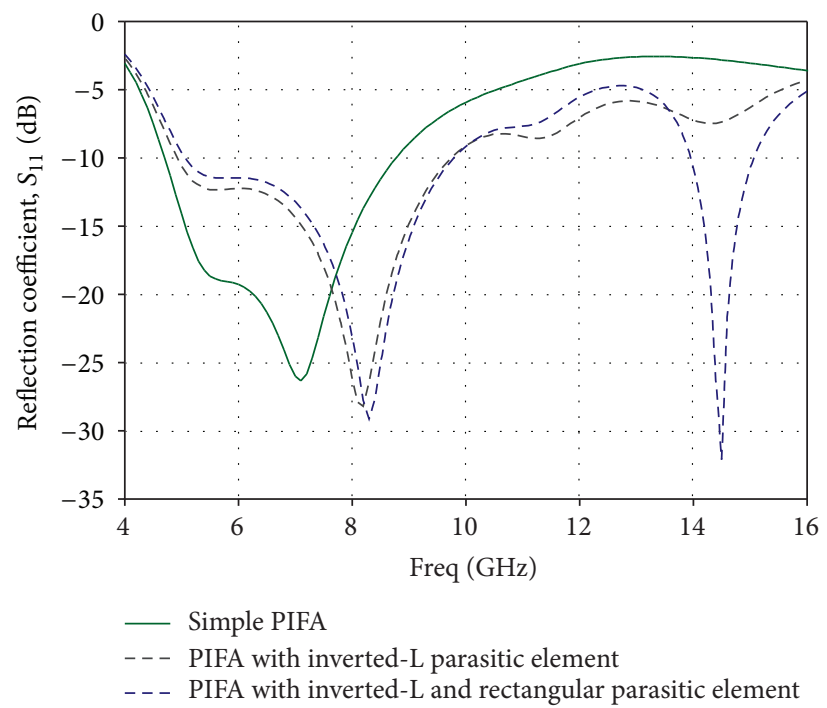

FIgURE 3: Magnitude of the simulated reflection coefficient of the PIFA with and without the inverted-L and rectangular shaped parasitic strips.

insertion of this parasitic element produces an additional resonance at around $15 \mathrm{GHz}$ band. The optimized parameters up to this point of our step by step design approach are as follows: $W_{G}=12 \mathrm{~mm}, L_{G}=18.4 \mathrm{~mm}, W_{\mathrm{sh}}=0.5 \mathrm{~mm}, W=12 \mathrm{~mm}, L=$ $6 \mathrm{~mm}, h=3 \mathrm{~mm}, W_{f}=5.5 \mathrm{~mm}, L_{b}=2.7 \mathrm{~mm}, D_{c}=0.3 \mathrm{~mm}$, $C_{L}=1.4 \mathrm{~mm}, d=0.4 \mathrm{~mm}$ and $t_{c}=0.5 \mathrm{~mm}$, and $D_{c 1}=1.4 \mathrm{~mm}$. Figure 3 shows the results for the above-mentioned design. To produce the required resonance at $10 \mathrm{GHz}$ band, the study was started, initially, with the insertion of a slot at the top plate, which further led us to the design of a multiband PIFA with a split-ring resonator etched on its top plate. This design not only produces a required resonance at $10 \mathrm{GHz}$ but also offers a band rejection at $8 \mathrm{GHz}$ band.

To study the response of the split-ring resonator, an extensive parametric study is conducted in order to achieve the aforementioned design. The horizontal length of the SRR, $L_{X}$, is varied from $4.5 \mathrm{~mm}$ to $7.5 \mathrm{~mm}$ and all other parameters are held constant at $L_{Y}=3.5 \mathrm{~mm}, W_{S}=0.5 \mathrm{~mm}, X_{S}=3 \mathrm{~mm}$,
$Y_{S}=2 \mathrm{~mm}, G_{S}=0.5 \mathrm{~mm}$, and $D_{g}=3.5 \mathrm{~mm}$. Figure 4 shows that by varying $L_{X}$, the notched frequency band is varied. An increment in $L_{X}$ decreases the notched frequency. On further investigations, a length $L_{X}=6.6 \mathrm{~mm}$ is chosen to obtain the required stop and pass frequency bands at around 8 and $10 \mathrm{GHz}$, respectively.

Similarly, $D_{g}$, the distance of the gap slot of the SRR from the vertical side of the SRR, is varied from $1.5 \mathrm{~mm}$ to $5.5 \mathrm{~mm}$, while all other parameters are held constant at $L_{X}=6.6 \mathrm{~mm}$, $L_{Y}=3.5 \mathrm{~mm}, W_{S}=0.5 \mathrm{~mm}, X_{S}=3 \mathrm{~mm}, Y_{S}=2 \mathrm{~mm}$, and $G_{S}$ $=0.5 \mathrm{~mm}$. It is observed that the notch band does not vary significantly with the variations in $D_{g}$; however, the variations in the level of reflection coefficient $S_{11}$ are important in passband near $10 \mathrm{GHz}$ as shown in Figure 5. An increment in $D_{g}$ slightly increases the second resonant frequency; however, after the value of $D_{g}=3.5 \mathrm{~mm}$, a further increase in its value deteriorates $S_{11}$ at that particular frequency. Therefore, the optimized value chosen for $D_{g}$ is $3.5 \mathrm{~mm}$. 


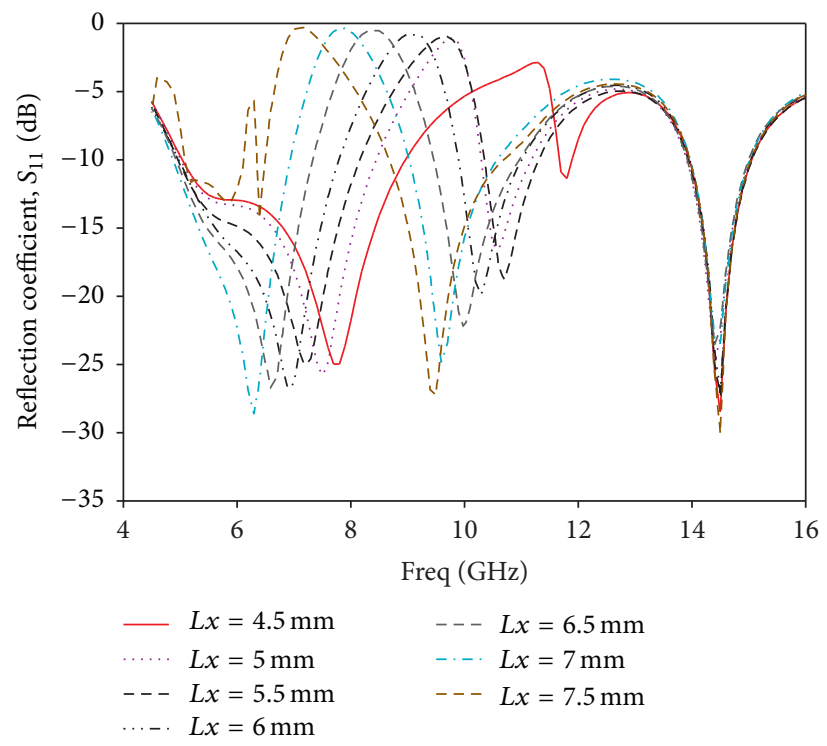

FIGURE 4: Magnitude of the simulated reflection coefficient of the PIFA versus frequency for different values of the geometrical parameter $L x$.

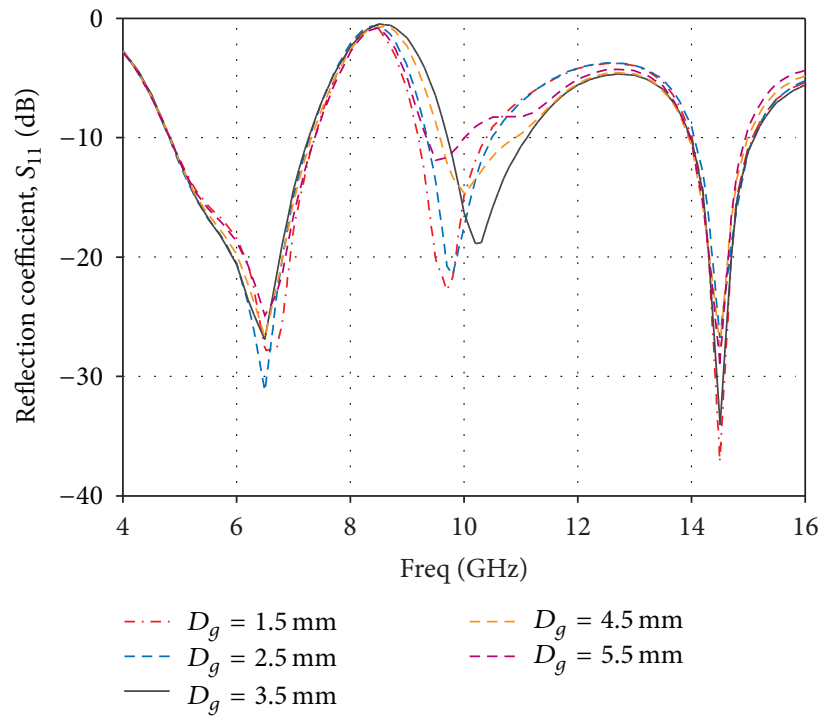

FIGURE 5: Magnitude of the simulated reflection coefficient of the PIFA versus frequency for different values of the geometrical parameter $D_{g}$.

Similarly, by increasing $W_{S}$ the notch band and the second resonant frequency move towards a higher value as shown in Figure 6. This behaviour is due to the reason that an increase in the value of $W_{S}$ decreases the current path length inside SRR and hence increases the rejection and passband frequency. Therefore, the final optimized design values for the SRR, chosen after extensive parametric study, are as follows: $L_{X}=6.6 \mathrm{~mm}, L_{Y}=3.5 \mathrm{~mm}, W_{S}=0.5 \mathrm{~mm}, X_{S}=3 \mathrm{~mm}, Y_{S}=$ $2 \mathrm{~mm}, G_{S}=0.5 \mathrm{~mm}$, and $D_{g}=3.5 \mathrm{~mm}$.

As discussed in [17], the surface current distribution is helpful towards explaining the phenomenon occurring due to the SRR. Therefore, the surface current distributions on the top plate of the SRR based PIFA excited at $8 \mathrm{GHz}$ and $10 \mathrm{GHz}$ are shown in Figure 7. Figure 7(a) shows a strong surface currents distribution excited at $8 \mathrm{GHz}$ causing an antiresonance at this frequency resulting in a band notch. Figure 7(b) shows a weaker surface current distribution excited at $10 \mathrm{GHz}$ that results in a resonance at about $10 \mathrm{GHz}$.

We have observed that the insertion of a split-ring resonator with an inner perimeter of about $18 \mathrm{~mm}$ introduces a band rejection at a frequency around $8 \mathrm{GHz}$ and further yields a resonance at $10 \mathrm{GHz}$. A highly sharp antiresonance occurs when the perimeter of the loop is about $\lambda / 2$ [18]. Impedance results in Figure 8 show that an antiresonance occurs at around $8 \mathrm{GHz}$ band. This is the reason towards the band notching at $8 \mathrm{GHz}$ where the SRR perimeter is about 


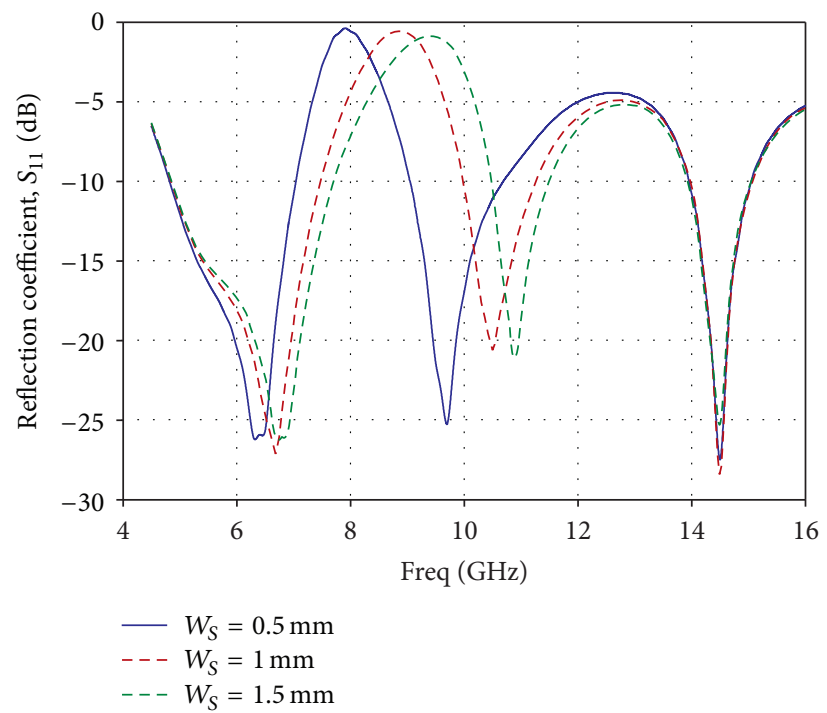

FIGURE 6: Magnitude of the simulated reflection coefficient of the PIFA versus frequency for different values of the geometrical parameter $W_{S}$.

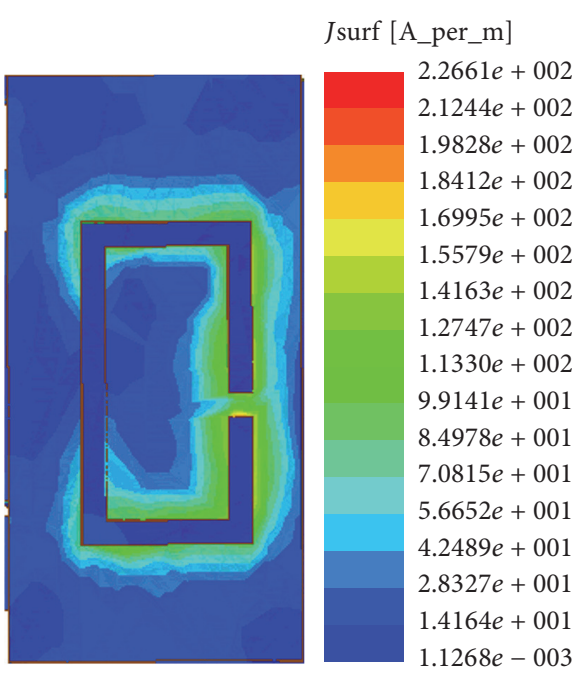

(a)

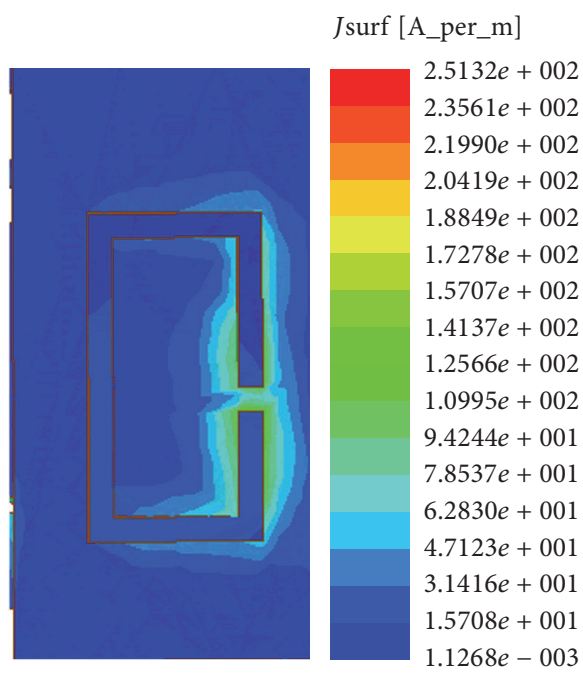

(b)

FIGURE 7: Surface current distribution on the top plate at (a) $8 \mathrm{GHz}$ and (b) $10 \mathrm{GHz}$.

$\lambda / 2$. And it starts resonating at around $10 \mathrm{GHz}$ where its perimeter $>0.6 \lambda$. It is observed that the inverted-L and the SRR together provide a resonance at $10 \mathrm{GHz}$ band.

\section{Results and Discussion}

The split-ring resonator based PIFA design has been simulated and optimized using Ansys Electromagnetics Suite 17.0 simulator package. The final optimized design parameters are as follows: $W_{G}=12 \mathrm{~mm}, L_{G}=18.4 \mathrm{~mm}, W_{\text {sh }}=0.5 \mathrm{~mm}, W$ $=12 \mathrm{~mm}, L=6 \mathrm{~mm}, h=3 \mathrm{~mm}, W_{f}=5.5 \mathrm{~mm}, L_{b}=2.7 \mathrm{~mm}$, $L_{X}=6.6 \mathrm{~mm}, L_{Y}=3.5 \mathrm{~mm}, W_{S}=0.5 \mathrm{~mm}, X_{S}=3 \mathrm{~mm}, Y_{S}=$ $2 \mathrm{~mm}, G_{S}=0.5 \mathrm{~mm}, D_{g}=3.5 \mathrm{~mm}, D_{c}=0.3 \mathrm{~mm}, C_{L}=1.4 \mathrm{~mm}$, $d=0.4 \mathrm{~mm}$ and $t_{c}=0.5 \mathrm{~mm}$, and $D_{c 1}=1.4 \mathrm{~mm}$. Figure 9 shows the simulated and the measured results for reflection coefficient $S_{11}$. The $S_{11}$ results show that the antenna covers simultaneously the $6 \mathrm{GHz}$ band $(4.8 \mathrm{GHz}$ to $7 \mathrm{GHz})$, the $10 \mathrm{GHz}$ band ( 9.5 to $10.8 \mathrm{GHz}$ ), and the $15 \mathrm{GHz}$ band (14$15 \mathrm{GHz})$. The simulated and the measured results show generally a very good agreement. Figure 10 shows the simulated and the measured radiation patterns of this antenna at $\phi=$ $0^{\circ}$ and $\phi=90^{\circ}$. The radiation patterns of this antenna are measured in an anechoic chamber. The maximum gains of this antenna at the frequencies $6 \mathrm{GHz}, 10 \mathrm{GHz}$, and $15 \mathrm{GHz}$ are $3.4 \mathrm{dBi}, 4.9 \mathrm{dBi}$, and $5.85 \mathrm{dBi}$, respectively.

\section{Conclusion}

A novel multiband SRR based modified PIFA design has been proposed. The antenna operated at the frequency 


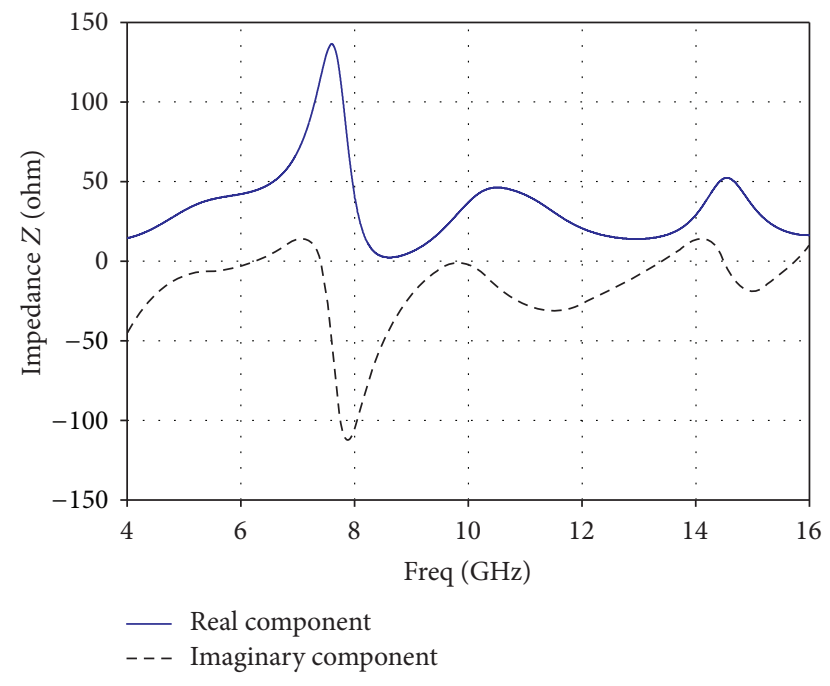

FIgURE 8: Impedance $Z(\Omega)$ versus frequency $(\mathrm{GHz})$.

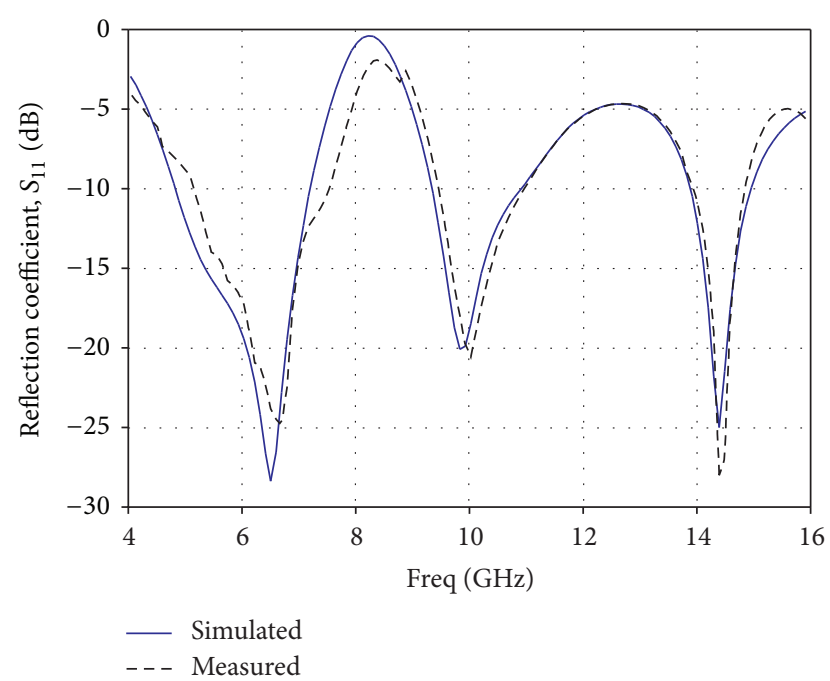

FIGURE 9: Magnitude of the simulated and measured reflection coefficient $S_{11}(\mathrm{~dB})$ versus frequency $(\mathrm{GHz})$ for SRR based PIFA.

bands located at $6 \mathrm{GHz}, 10 \mathrm{GHz}$, and $15 \mathrm{GHz}$, expected to be included in the upcoming $5 \mathrm{G}$ wireless communication standards. It was observed that an SRR with a width of $0.5 \mathrm{~mm}$, etched on the top plate of the PIFA, having a perimeter, $\lambda / 2$, provided a band rejection around $8 \mathrm{GHz}$. It also provided a resonance around $10 \mathrm{GHz}$ band, where the SRR perimeter was greater than or equal to about $0.6 \lambda$. The SRR based PIFA with the parasitic elements radiated at $6 \mathrm{GHz}, 10 \mathrm{GHz}$, and $15 \mathrm{GHz}$ bands in such a way that the basic PIFA structure radiated at $6 \mathrm{GHz}$, whereas the inclusion of an SRR etched on the top plate, and inverted-L parasitic element together caused a radiation at $10 \mathrm{GHz}$ band. Further, an insertion of a rectangular parasitic element caused the antenna to radiate at $15 \mathrm{GHz}$ band. When the perimeter of the SRR became equal to $\lambda / 2$ at $8 \mathrm{GHz}$, the antenna radiated poorly causing a sharp gain drop. This happened because an antiresonance occurred at this particular frequency. For the resonant frequency bands

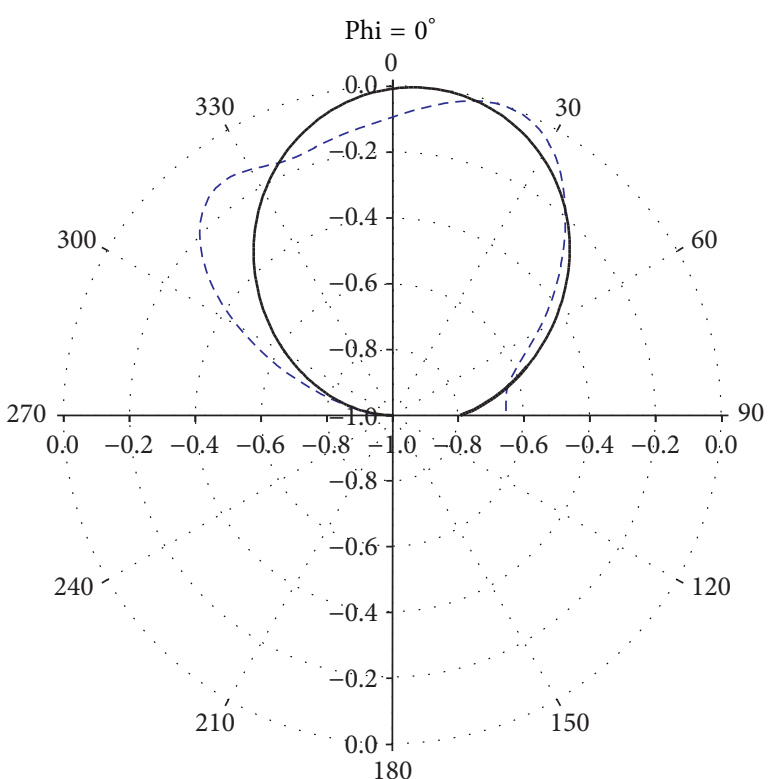

-- Measured

- Simulated

(a)

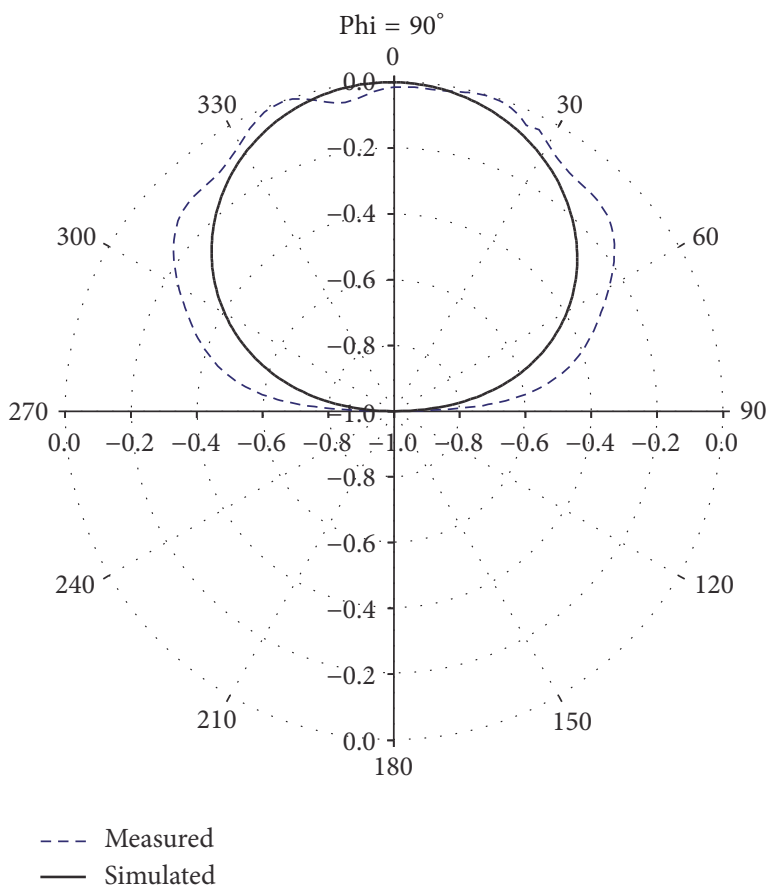

(b)

FIGURE 10: Simulated and measured 2D radiation patterns of SRR based PIFA for $6 \mathrm{GHz}$ at (a) $\phi=0^{\circ}$ and (b) $\phi=90^{\circ}$.

of 6,10 , and $15 \mathrm{GHz}$, the peak gains were $3.4 \mathrm{dBi}, 4.9 \mathrm{dBi}$, and $5.85 \mathrm{dBi}$, respectively.

\section{Conflicts of Interest}

The authors declare that there are no conflicts of interest regarding the publication of this paper. 


\section{References}

[1] J. G. Andrews, S. Buzzi, W. Choi et al., "What Will 5 G Be?" IEEE Journal on Selected Areas in Communications, vol. 32, no. 6, pp. 1065-1082, 2014.

[2] Q. Wang, B. Ai, K. Guan, D. W. Matolak, R. He, and X. Zhou, "Ray-based statistical propagation modeling for indoor corridor scenarios at $15 \mathrm{GHz}$," International Journal of Antennas and Propagation, vol. 2016, Article ID 2523913, 12 pages, 2016.

[3] G. Fettweis and S. Alamouti, "5G: personal mobile internet beyond what cellular did to telephony," IEEE Communications Magazine, vol. 52, no. 2, pp. 140-145, 2014.

[4] F. Khan, Z. Pi, and S. Rajagopal, "Millimeter-wave mobile broadband with large scale spatial processing for $5 \mathrm{G}$ mobile communication," in Proceedings of the 50th Annual Allerton Conference on Communication, Control, and Computing (Allerton '12), pp. 1517-1523, IEEE, October 2012.

[5] Ofcom, Spectrum above $6 \mathrm{GHz}$ for Future Mobile Communications, Ofcom, London, UK, 2015.

[6] H. T. Chattha, Y. Huang, M. K. Ishfaq, and S. J. Boyes, "A Comprehensive Parametric Study of planar inverted-F antenna," Scientific Research Wireless Engineering and Technology, vol. 3, no. 1, pp. 1-11, 2012.

[7] H. T. Chattha, Y. Huang, M. K. Ishfaq, and S. J. Boyes, "Bandwidth enhancement techniques for planar inverted-F antenna," IET Microwaves, Antennas \& Propagation, vol. 5, no. 15, pp. 1872-1879, 2011.

[8] P. Li, J. Pan, D. Yang, and P. Nie, "A novel dual-shorting point PIFA (GSM850 to IMT-A) for mobile handsets," International Journal of Antennas and Propagation, vol. 2013, Article ID 436808, 7 pages, 2013.

[9] N. Chattoraj, J. Qurratulain, S. Agarwal, and K. V. Singh, "Design of a novel dual: band planar inverted F-antenna for mobile radio applications," Journal of Microwaves, Optoelectronics and Electromagnetic Applications, vol. 13, no. 2, pp. 177-184, 2014.

[10] J. Yang, X.-L. Li, and W.-L. Zhao, "Triple broadband compact planar inverted F antenna for WLAN and WiMAX," Journal of China Universities of Posts and Telecommunications, vol. 17, no. 1, pp. 32-36, 2010.

[11] H. T. Chattha, M. K. Ishfaq, Y. Saleem, Y. Huang, and S. J. Boyes, "Band-notched ultrawide band planar inverted-F antenna," International Journal of Antennas and Propagation, vol. 2012, Article ID 513829, 6 pages, 2012.

[12] K. R. Boyle and P. G. Steeneken, "A five-band reconfigurable PIFA for mobile phones," IEEE Transactions on Antennas and Propagation, vol. 55, no. 11, pp. 3300-3309, 2007.

[13] H. T. Chattha, Y. Huang, Y. Lu, and X. Zhu, "An ultra-wideband planar inverted-F antenna," Microwave and Optical Technology Letters, vol. 52, no. 10, pp. 2285-2288, 2010.

[14] M. S. Ahmad, C. Y. Kim, and J. G. Park, "Multishorting pins PIFA design for multiband communications," International Journal of Antennas and Propagation, vol. 2014, Article ID 403871, 10 pages, 2014.

[15] H. Jian-rong, L. Jiu-sheng, and W. Di, "A small planar antenna for 4G mobile phone application," International Journal of Antennas and Propagation, vol. 2016, Article ID 4791831, 7 pages, 2016.

[16] H. T. Chattha, Y. Huang, and Y. Lu, "PIFA bandwidth enhancement by changing the widths of feed and shorting plates," IEEE Antennas and Wireless Propagation Letters, vol. 8, pp. 637-640, 2009.
[17] D. Caratelli, R. Cicchetti, G. Bit-Babik, and A. Faraone, "A perturbed E-shaped patch antenna for wideband WLAN applications," IEEE Transactions on Antennas and Propagation, vol. 54, no. 6, pp. 1871-1874, 2006.

[18] C. A. Balanis, Antenna Theory: Analysis and Design, John Wiley \& Sons, 3rd edition, 2005. 


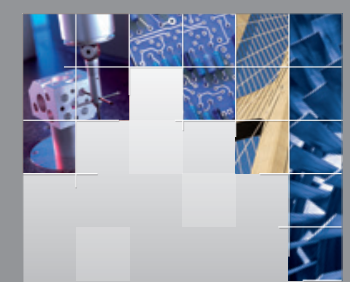

\section{Enfincering}
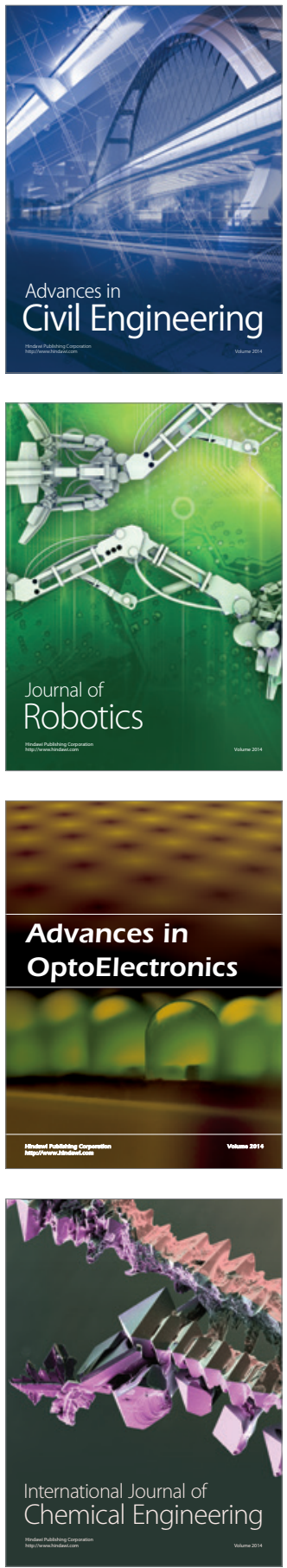

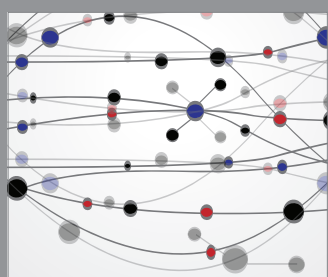

The Scientific World Journal

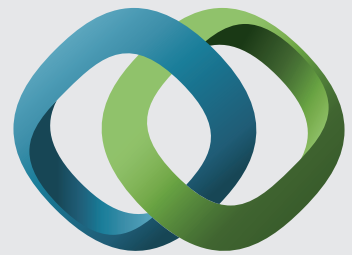

\section{Hindawi}

Submit your manuscripts at

https://www.hindawi.com
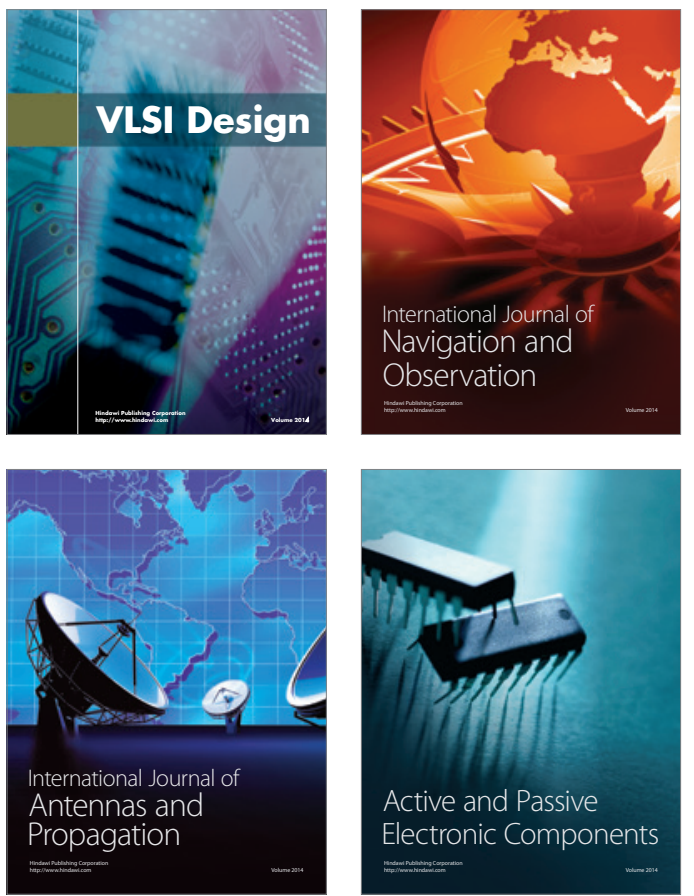
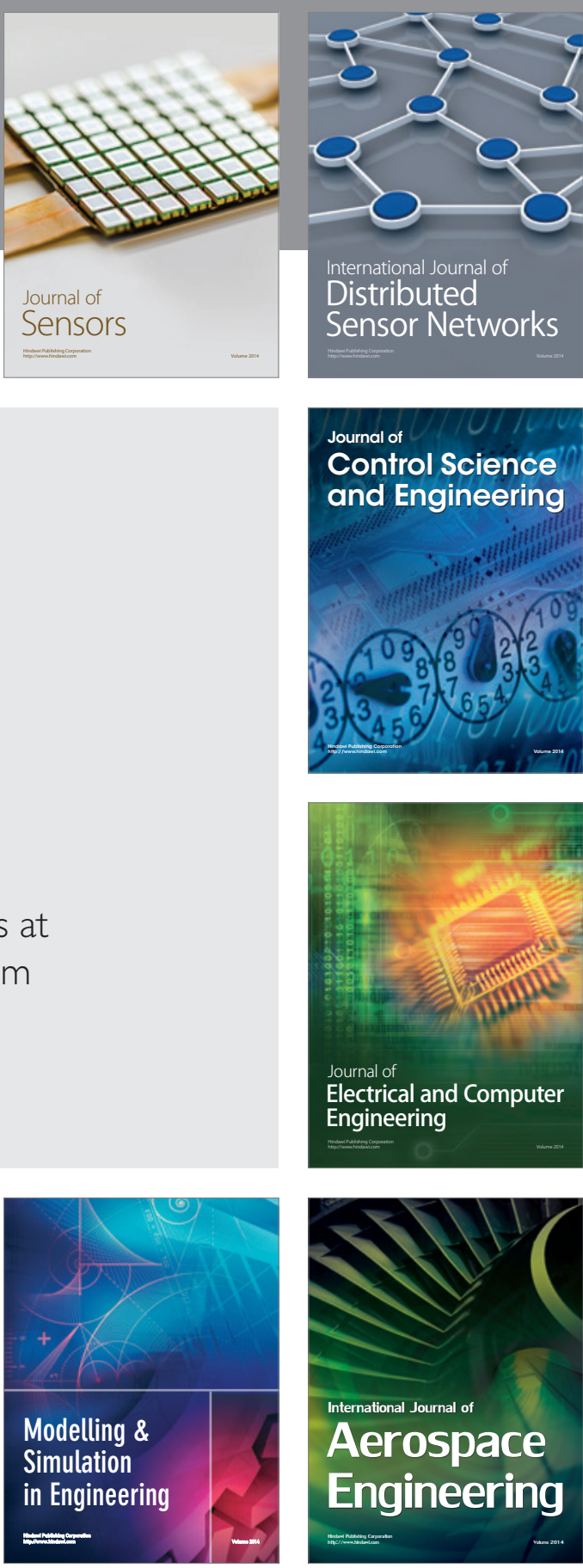

International Journal of

Distributed

Sensor Networks

$-$

Joumal of

Control Science

and Engineering
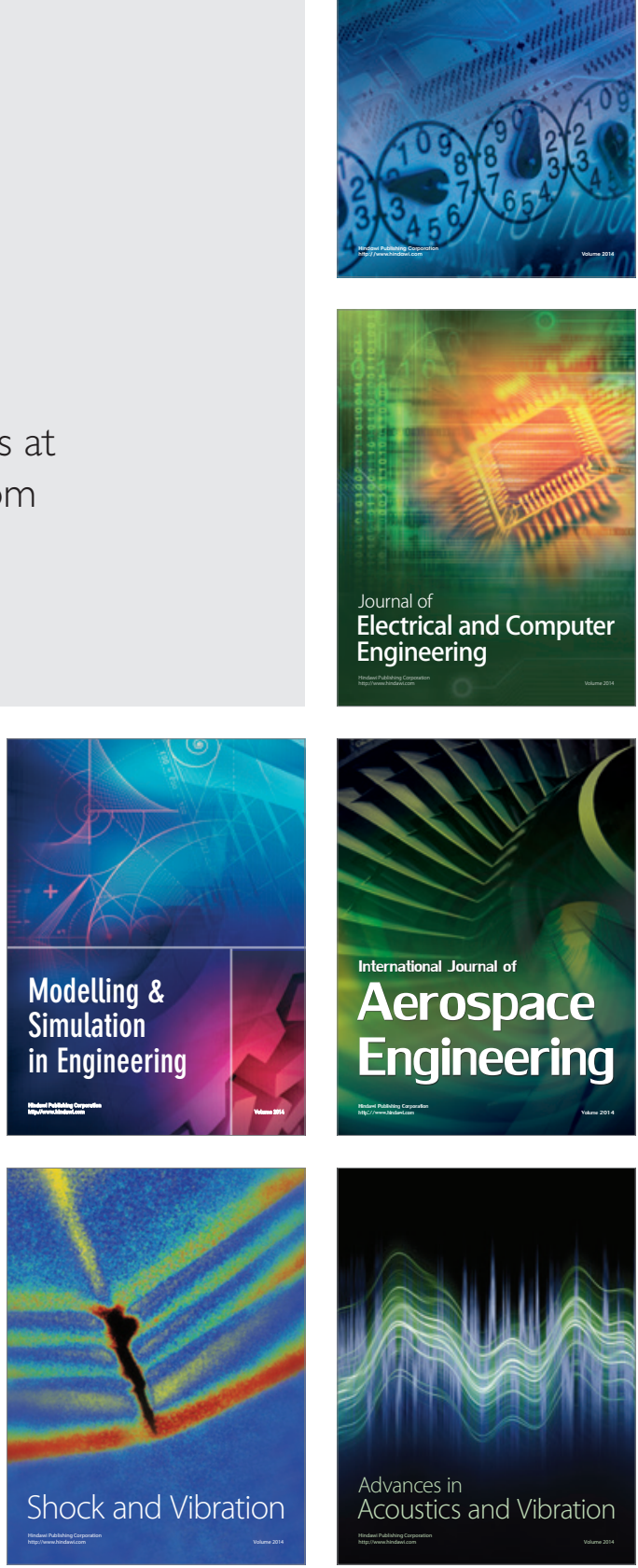